\title{
Climacterium, Climacteric Disturbance and Rejuvenation of Sex Center
}

By

\author{
Katsuji Kushima, Kenji Kamio and Yoshihiro Okuda \\ The Department of Obstetrics and Gynecology, Tohoku University School \\ of Medicine, Sendai, Director; Prof. K. Kushima
}

(Received for publication, April 4, 1961)

\section{INTRODUCTION}

No one would object to the proposition that climacterium means the stage of incipient senility, but there are few works giving more concrete attention to it. It is also generally accepted that climacterium begins when the ovary begins to show signs of senescence, but no one has proved it and it is not yet known whether this hypothesis is tenable. The cases of sundry climacteric disturbances are attributed to a "deficiency of ovarian hormones", but we feel justified in raising questions against this generalization. The present authors have been engaged in making researches to solve such questions on climacterium and climacteric disturbances for the past 10 years. In the following, the results of these studies are presented, together with a discussion on the relief from climacterium, that is, rejuvenation of the sex center.

Definition of climacterium and climacteric disturbances

Climacterium is generally defined as the transitional stage between maturity and senility, but such a vague definition is of little help for detailed investigation. Squires" gives the definition of "the stage for adaptation to the changes of the ovarian function, accompanying menopause", but in climacterium, not only the ovaries but all the endocrine organs are subject to functional changes. Therefore, the present authors wish to propose the definition of "the stage of abnormal fluctuation of the endocrine functions observed before and after the menopause" for climacterium.

The definition of climacteric disturbances hereunder will be "the diseases mainly consisting of autonomic nervous syndrome observed in climacterium". Accordingly, the climacteric disturbances comprise the symptoms occasioned by disturbance of the autonomic nervous center in the diencephalon due to the dysfunction of the endocrine system and the autonomic nervous syndrome caused by the emotional stress involved in senescence. Hitherto, uterine hemorrhage

九嶋 勝司, 神尾 慧治, 奥田 宣弘 
and climacteric melancholy have been included under the climacteric disturbances, but since these may be set aside as climacteric bleeding and involution melancholia, they will be excluded from the following study.

Is the ovary the first organ to show senescence?

The traditional proposition that the climacteric disturbances are caused by a deficiency of ovarian hormones has misled many authors in the belief that the ovary is the first of all endocrine organs to fall into senescence. When the ovaries of an old white rat above 650 days of age with complete cessation of estrous cycle and that of mature rat were bilaterally exchanged, the sexual cycle of the mature rat was kept intact but the vaginal cycle was not revived in the old rat provided with the ovaries of mature rat (Fig. 1). Therefore, it would seem reasonable to assume that the first organ to fall into senescence cannot be the ovary but some other central hormonal organ. Now, when the hypophysis of a sexually matured female rat is removed, it loses its estrual cycle, but when hypophysis is transplanted from a male rat, it regains the estrous cycle (Fig. 2). It follows that the hypophysis has no sexual difference. As the climacterium is not clearly detectable in male animals, it is difficult to suppose that the climacteric changes begin by occurring in the hypophysis. So, we are finally driven to the hypothalamus containing the sex center as the last resort.

after $\longleftrightarrow$ before
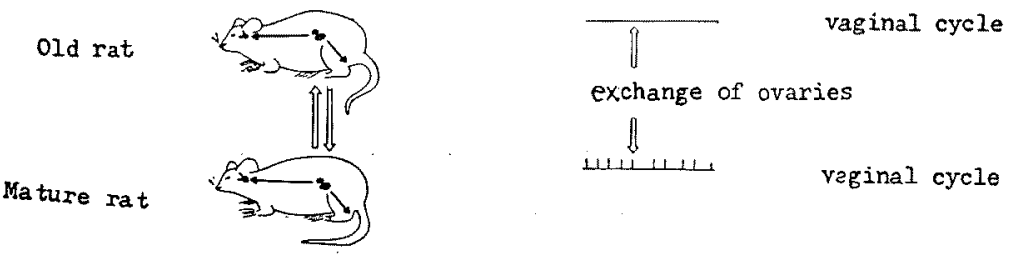

Fig. 1. Vaginal cycle in matured and senile rats after bilateral exchange of ovaries.
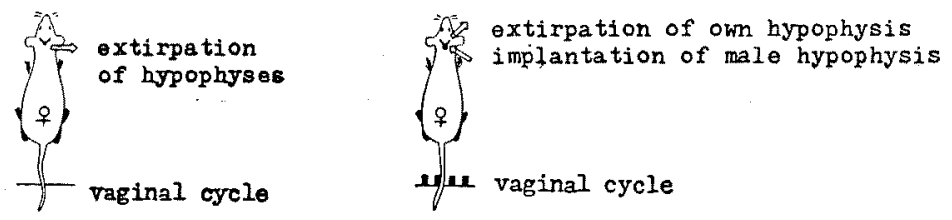

Fig. 2. Vaginal cycle after implantation of the male hypophysis in the hypophysectomized rat.

Senescence of diencephalon

Few, if any, authors have treated the subject of senescence of the diencephalon. The present authors, using the diencephala of old white rats showing no 
TABLE I. Secondary Fluorescence of Nucleus Paraventricularis Hypothalamics of the Rat.

\begin{tabular}{|c|c|c|c|c|c|c|}
\hline & \multirow{2}{*}{ No. } & \multicolumn{2}{|c|}{ Ganglion cell } & \multirow{2}{*}{ Glia cell } & \multicolumn{2}{|c|}{ Vessel } \\
\hline & & Cytoplasma & Nucleus & & Wall & Nucleus \\
\hline \multirow{3}{*}{ Mature rat } & 1. & dark orange & dark orange & greenish orange & yellowish green & orange \\
\hline & 2. & $n$ & " & " & " & " \\
\hline & 3. & $"$ & $"$ & $"$ & $"$ & $"$ \\
\hline \multirow{3}{*}{ Old rat } & 4. & brown & brown & greenish brown & \multirow{3}{*}{\multicolumn{2}{|c|}{$\begin{array}{c}\text { greenish brown yellowish brown } \\
" \prime\end{array}$}} \\
\hline & 5. & $"$ & $"$ & " & & \\
\hline & 6. & $"$ & $"$ & $"$ & & \\
\hline
\end{tabular}

more estrous cycles and mature white rats, measured the tissue respiration quotient $\left(\mathrm{QO}_{2}\right)$ with a Warburg's manometer, the gomoriphil substance by Halmi's method, the acetylcholine (Ach) content by use of the M. rectus abdominalis of frog and the cholinesterase (ChE) content by Koelle's method, and obtained the results shown in Figs. 3-6.

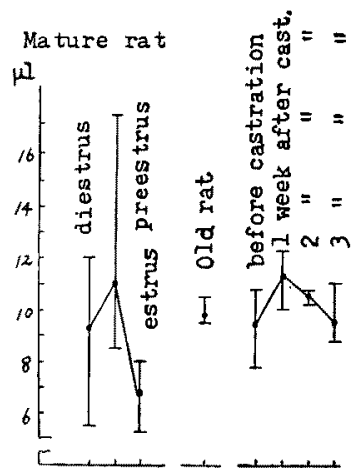

Fig. 3. $\mathrm{QO}_{2}$ of diencephalon.

Mature rat

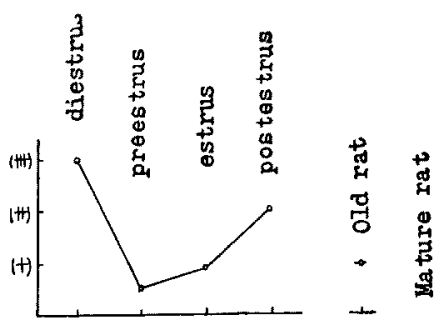

Fig. 5. Gomoriphil substance of hypothalamus.

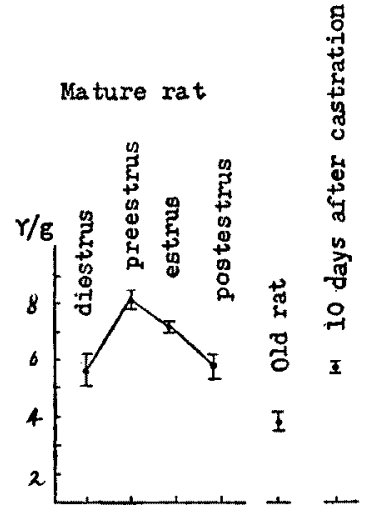

Fig. 4. Ach of diencephalon.
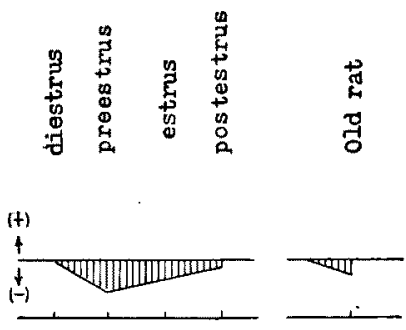

Fig. 6. ChE of nucleus supraopticus hypothalami. 
The diencephalic $\mathrm{QO}_{2}$ was slightly higher in the old rat than in the mature in diestrus, while the Gomoriphil substance and $\mathrm{ChE}$ in the old rat were nearly on the same level as the values in the mature rat in estrus, but Ach was lower in the old than in the mature rat in any stage of estrous cycle. The values of $\mathrm{QO}_{2}$ and Ach were measured in castrated rats and obtained results showed that senescence and castration have different effects on the values. The hypothalamus is influenced by estradiol injection. When mature rats in diestrus were subcutaneously injected with $100 \gamma$ of estradiol, the diencephalic $\mathrm{QO}_{2}$ rose significantly, but in old rats only a slight rise was observed (Fig. 7). In similar tests, the Ach content was considerably higher in mature rats, but rather low in old rats (Fig. 8). When the doses were doubled, the $\mathrm{ChE}$ content in the nucleus supraopticus was significantly reduced in mature rats, but only very slightly in old rats (Fig. 9). These results show that when the diencephalon becomes senescent, its sensitivity to estradiol is diminished.

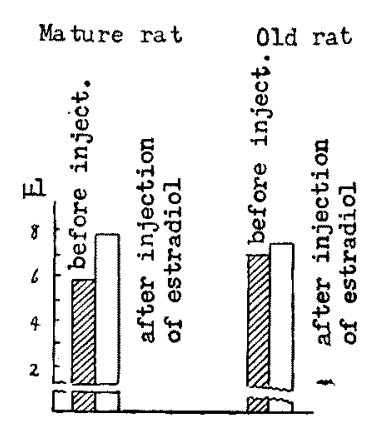

Fig. 7. $\mathrm{Qo}_{2}$ of diencephalon.

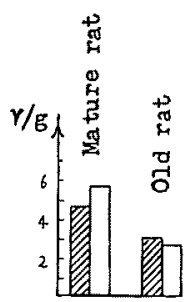

Fig. 8. Ach of diencephalon.

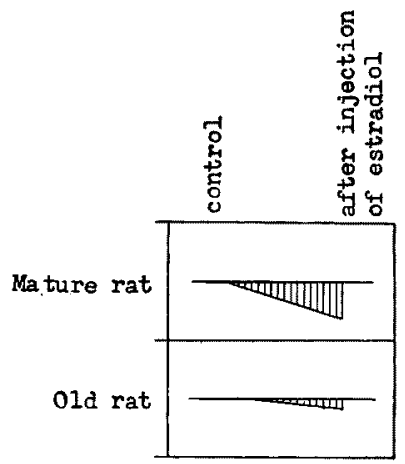

Fig. 9. ChE of nucl. supraopticus.

The secondary fluorescence emitted by young tissues stained with acridinorange for one minute is greenish, that is the color of rather short wave-length, but in older tissues, the color changes to of longer wave-lengths, through yellow to 
orange, brown and finally to red. The diencephalic tissue of old rats, as shown in Fig. 10, showed secondary fluorescences of longer wave-length than those of younger rats. A similar trend was observed in specimens of human diencephalon (Table II and Fig. 2). In the human hypothalamus, the paraventricular, supraoptic and tuberal nuclei, all became senescent at nearly equal paces and the change of the color became particularly evident after menopause, but the fornix showed little change in this respect.

TABLE II. Secondary Fluorescence of Human Diencephalon.

\begin{tabular}{|c|c|c|c|c|c|c|}
\hline Age & $\begin{array}{l}\text { After } \\
\text { death }\end{array}$ & $\begin{array}{l}\text { Menst- } \\
\text { ruation }\end{array}$ & Clinical diagnosis & $\begin{array}{c}\text { Ganglion cell } \\
\text { of } \\
\text { nucl. para- } \\
\text { ventricularis }\end{array}$ & $\begin{array}{l}\text { Substantia } \\
\text { gelatinosa }\end{array}$ & Fornix \\
\hline $\begin{array}{l}\text { yrs. } \\
18\end{array}$ & $\begin{array}{l}\text { hs. } \\
3\end{array}$ & $(+)$ & acute leucemia & orange & yellowish green & yellowish green \\
\hline 21 & 2 & $(+)$ & aplastic anemia & $n$ & $"$ & green \\
\hline 35 & 8 & $(+)$ & chorionepithelioma & yellowish brown & $"$ & $"$ \\
\hline 40 & 5 & $(+)$ & uremia & orange & dark orange & " \\
\hline 42 & 2 & $(+)$ & sarcoma of larynx & yellowish brown & $"$ & $"$ \\
\hline 53 & 9 & $(-)$ & acute leucemia & dark brown & $"$ & " \\
\hline 64 & 2 & $(-)$ & $\begin{array}{c}\text { subarachnoidal } \\
\text { bleeding }\end{array}$ & $"$ & $"$ & $"$ \\
\hline 64 & 1 & $(-)$ & cancer of esophagus & $"$ & $"$ & " \\
\hline
\end{tabular}

Note: Acridin-orange staining, $1 \mathrm{~min}$.

\section{Climacteric disturbance and hormones}

I) Estrogen : Seeing that climacteric disturbances occur just before and after menopause, castration causing similar disturbances and estrogen effective in curing such disturbances, many investigators believe that climacteric disturbances result from deficiency of estrogen. But upon determination of urinary estrogen of patients with climacteric disturbances, it was found that the value was high in some cases and low in the other showing no definite tendency (Kurzrock $^{21}$, Tamis ${ }^{3)}$, Berger et al. $\left.{ }^{4}\right)$. In consideration of the possible periodic rise and fall of the estrogen secretion, the urinary estrogen value of an adult woman and a woman in climacterium were estimated over one month, and it was found that estradiol, estron and estriol were all rather in higher content in the urine of the climacteric woman, as shown in Figs. 12 and 13.

Yamada, one of the co-workers, has made a comparative study of the quantity of estrogen produced upon incubation of the ovary of adult women with gonadotrophin and testosterone, and a similar incubation test with the ovary from climacteric women, and found that the ability of elaborating estogen in most of the climacteric ovaries was not inferior to that of mature ovaries. The 
TABLE III. Estrogen Produced after Incubation of $1 \mathrm{~g}$. of Human Ovary with 1,000 $\gamma$ of Testosterone and Gonadotrophin.

\begin{tabular}{|c|c|c|c|c|c|c|c|c|}
\hline \multirow{2}{*}{ No. } & \multirow{2}{*}{ Age } & \multirow{2}{*}{$\begin{array}{l}\text { After } \\
\text { menopause }\end{array}$} & \multicolumn{2}{|c|}{$\begin{array}{l}\text { Estradiol } \\
\text { fraction }\end{array}$} & \multicolumn{2}{|c|}{$\begin{array}{l}\text { Estrone } \\
\text { fraction }\end{array}$} & \multicolumn{2}{|c|}{ Total estrogen } \\
\hline & & & $\gamma$ & $\%$ & $\gamma$ & $\%$ & $\gamma$ & $\%$ \\
\hline 1. & $\begin{array}{l}\text { yrs. } \\
46\end{array}$ & \multirow{6}{*}{$\begin{array}{l}\text { menstruation } \\
\qquad(+)\end{array}$} & 5.0 & 0.50 & 5.8 & 0.58 & 10.8 & 1.08 \\
\hline 2. & 34 & & 7.2 & 0.72 & 3.2 & 0.32 & 10.4 & 1.04 \\
\hline 3. & 39 & & 3.5 & 0.35 & 7.0 & 0.70 & 10.5 & 1.05 \\
\hline 4. & 38 & & 7.4 & 0.74 & 5.3 & 0.53 & 12.7 & 1.27 \\
\hline 5. & 48 & & 7.1 & 0.71 & 3.0 & 0.30 & 10.1 & 1.01 \\
\hline 6. & 43 & & 9.0 & 0.91 & 7.0 & 0.70 & 16.0 & 1.61 \\
\hline 7. & 44 & $\begin{array}{l}\text { yrs. } \\
0.07\end{array}$ & 13.0 & 1.30 & 7.0 & 0.70 & 20.0 & 2.00 \\
\hline 8. & 48 & 2 & 3.7 & 0.37 & 0 & 0 & 3.7 & 0.37 \\
\hline 9. & 56 & 3 & 3.0 & 0.30 & 3.5 & 0.35 & 6.0 & 0.60 \\
\hline 10. & 49 & 0.06 & 8.1 & 0.81 & 7.2 & 0.72 & 15.3 & 1.53 \\
\hline 11. & 57 & 2 & 0 & 0 & 0 & 0 & 0 & 0 \\
\hline
\end{tabular}

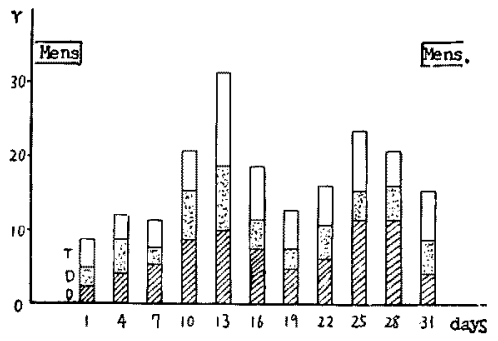

Fig. 12. Urinary estrogens of a normal woman of 32 years.

Note : T....estriol
D....estradiol

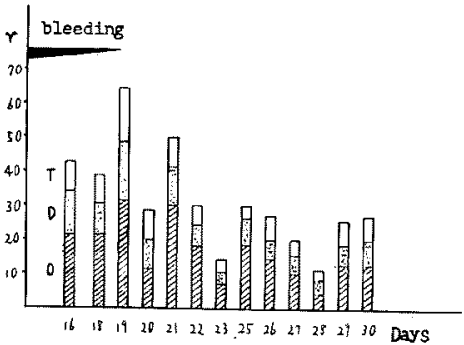

Fig. 13. Urinary estrogens of 46 years old woman with climacteric disturbance.

TABLE IV. Estradiol Produced after Incubation of Rabbit's Suprarenal Gland with $400 \gamma$ of Estrone and Gonadotrophin.

\begin{tabular}{l|c|c|c|c|c}
\hline & & & \multirow{2}{|c|}{$\begin{array}{c}\text { Weight of } \\
\text { suprarenal } \\
\text { gland } \\
\end{array}$} & No. & \multicolumn{2}{|c}{$\begin{array}{c}\text { Produced } \\
\text { estradiol }\end{array}$} \\
\cline { 4 - 7 } & & $(\mathrm{g})$ & $\gamma \mathrm{g})$ & $\gamma$ & $\%$ \\
\hline \multirow{3}{*}{ Non-castrated rabbit } & 1. & 2540 & 315 & 8.0 & 2.0 \\
& 2. & 2010 & 385 & 0 & 0 \\
& 3. & 1980 & 235 & 0 & 0 \\
\hline \multirow{3}{*}{ Castrated rabbit } & 4. & 2175 & 336 & 13.0 & 3.2 \\
& 5. & 1875 & 232 & 9.0 & 2.2 \\
& 6. & 2500 & 317 & 14.0 & 3.0
\end{tabular}


Fig. 10 Secondary fluorescence of rat diencephalon

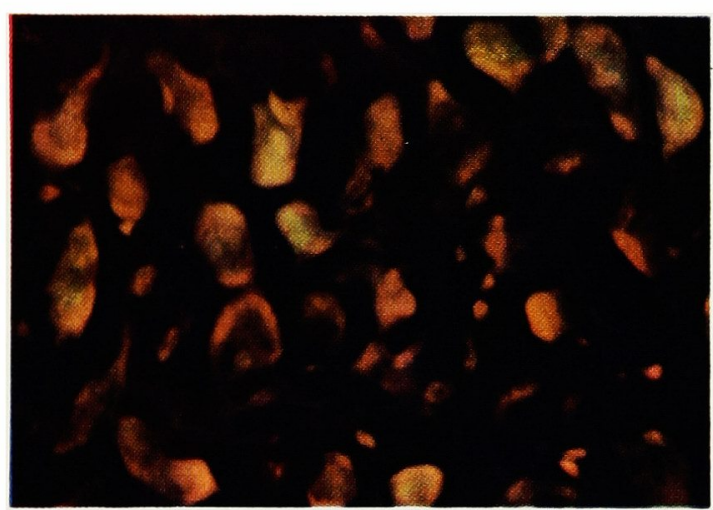

a) Young rat

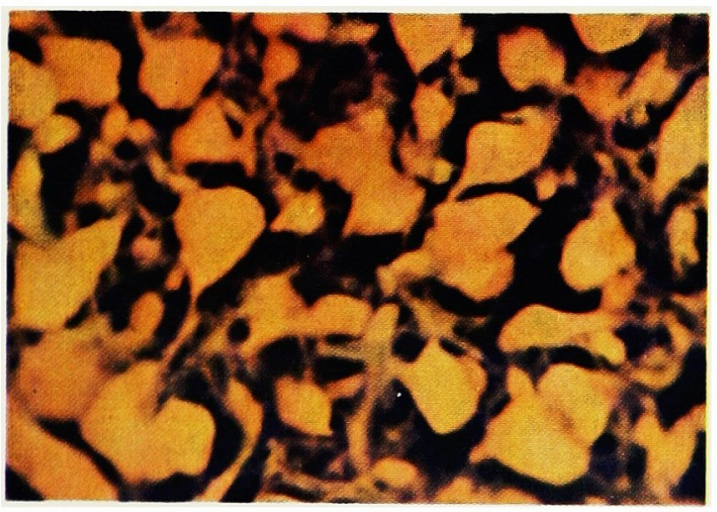

b) Old rat 
Fig. 11 Secondary fluorescence of human diencephalon

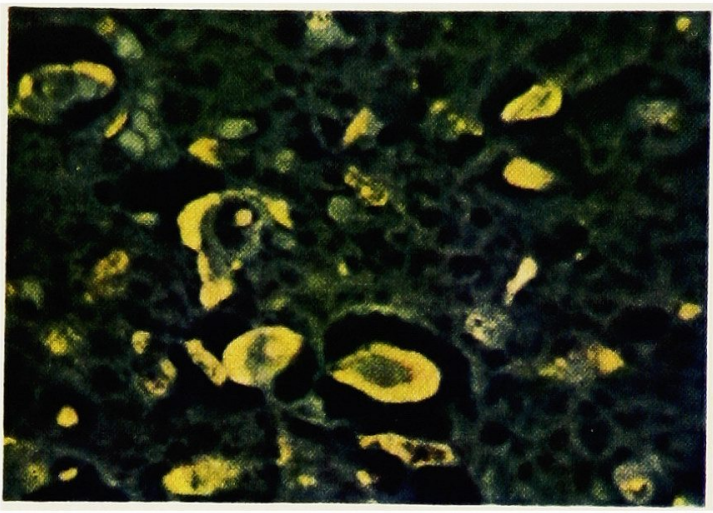

a) Young woman

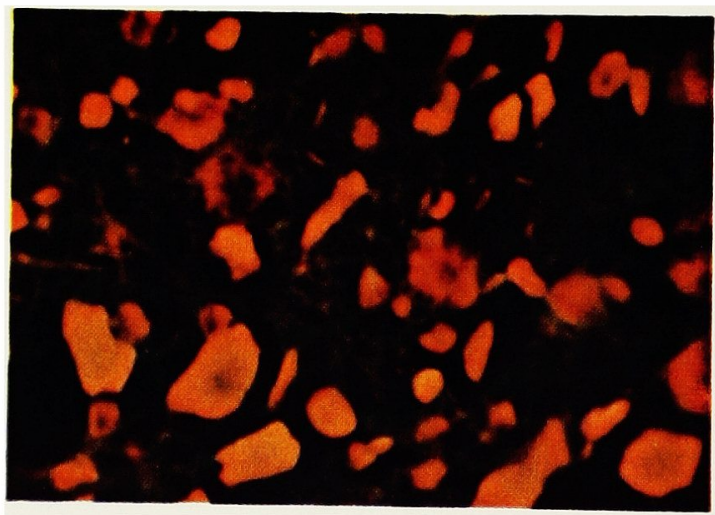

b) Old woman 
suprarenal gland normally secretes chiefly estrone, but after castration, it secreted estradiol (Table IV). Thus, after oophorectomy, the suprarenal gland replace the ovary in the function of secreting estradiol. These findings show the untenability of the hypothesis that climacteric disturbances are attributed to the effect of decreased estrogen secretion.

II) Gonadotrophin: Numerous authors have reported on the increase of the urinary content of follicle stimulating hormone (FSH) in subjects with climacteric disturbances (Zondek ${ }^{5)}$, Engel ${ }^{8}$, Henderson et $a .^{71}$, Witschi et $a .^{8}{ }^{8}$, Fluhmann ${ }^{9}$, Albright ${ }^{10)}$, Engelhart et al11), etc.), but the present authors demonstrated that, as shown in Table $\mathrm{V}$ the urinary FSH content was not always high in patients with climacteric symptoms. Frank et al. state that FSH increases with the appearance of climacteric disturbances and decreases with the disappearance of the syndrome. According to what we have observed, however, as shown in Fig. 14, although some cases showed decrease of FSH with the alleviation of symptoms (A), in some other cases on whom complete remission was obtained by estrogen injection, FSH dropped temporarily with alleviation of the symptoms following estrogen administration but rose again to about twice the pretreatment value on the 14th day when no symptoms were present. From these experimental results and the fact that $80 \%$ of climacteric disturbance cases are cured by estrogen therapy while FSH level often increased by rebound phenomenon after estrogen injection, it must be inferred that increase of FSH is not the cause of climacteric disturbances.

TABLE V. FSH in Urine.

\begin{tabular}{c|r|r|r|r|r|r}
\hline Mouse unit per liter & $>10$ & 10 & 20 & 40 & 80 & 160 \\
\hline Climacteric women without disturbance & Cases & 2 & 3 & 2 & 1 & \\
Climacteric women with disturbance & 2 & 10 & 10 & 8 & 10 & 4
\end{tabular}
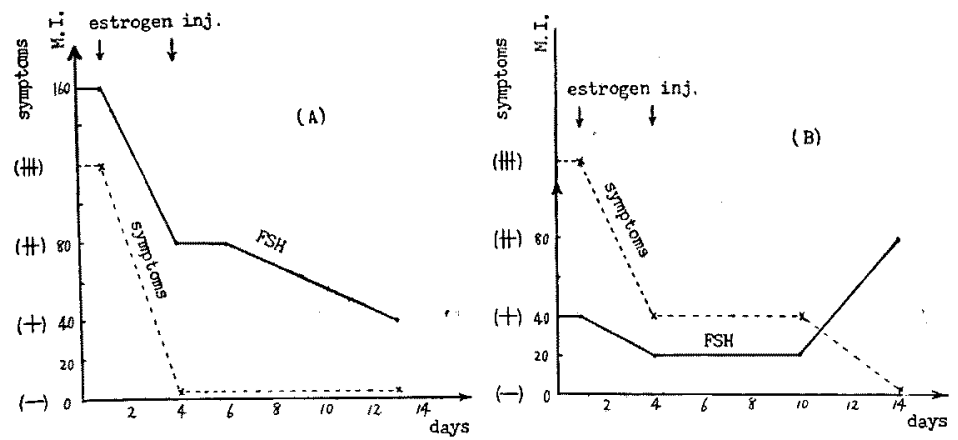

Fig. 14. FSH in urine and symptoms in the elimacteric patient subjected to estrogen therapy. 
III) Other hormones: No perceptible change was observed in the pregnanediol content in urine of the cases of climacteric disturbances (Fig. 15). The 17-OH-corticoid content in urine was subnormal in some cases but quite normal in others (Fig. 16). The content of 17-KS in urine, ACTH in plasma and TSHlike substance in whole blood were increased only in some of the cases with climacteric disturbances. In short, the hormones in subjects with climacteric disturbances often show abnormal changes, but not enough consistency is found to justify the consideration of these abnormality as the cause of the climacteric disturbances.

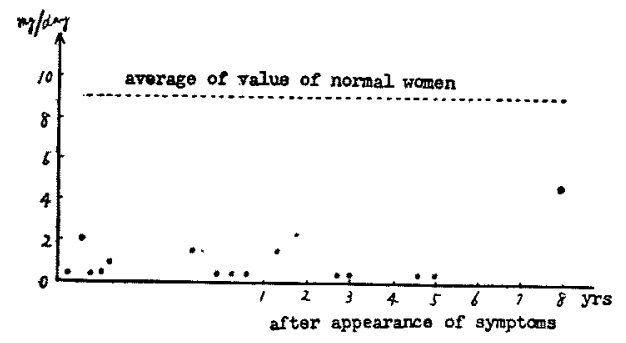

Fig. 15. Pregnanediol in urine of climacteric disturbance.

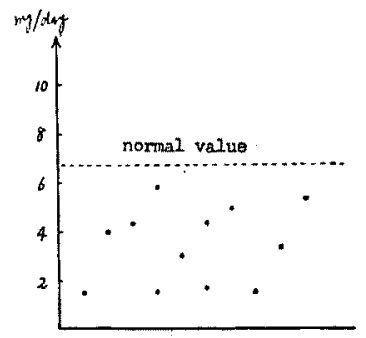

Fig. 16. Glucocorticoid in urine of climacteric disturbance.

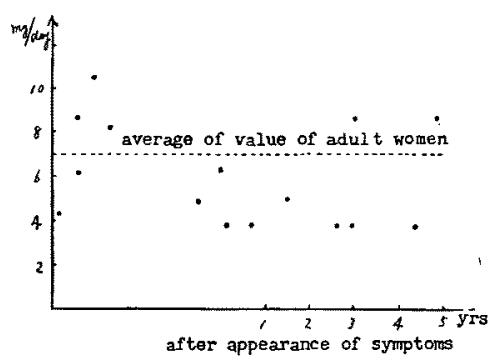

Fig. 17. 17-KS in urine of climacteric disturbance.

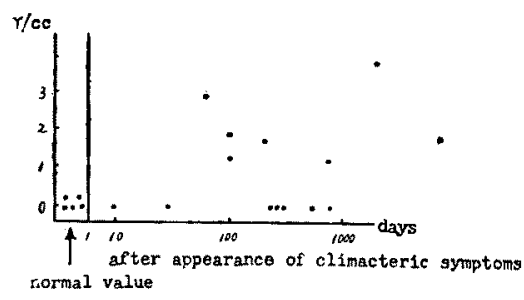

Fig, 18. ACTH in plasma.

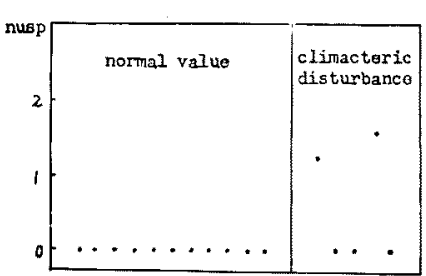

Fig. 19. TSH like substance in blood $(10 \mathrm{cc})$

Climacteric symptoms and autonomic nervous function

As stated above, the climacteric disturbances mainly consist in autonomic nervous syndrome. Accordingly, we proceeded to examine the autonomic nervous 
function of women with cilmacteric disturbances. The examination was carried out following the methods which we have devised and which is based on the blood-pressure coefficient $\left(C_{B}\right)$, the pulse coefficient $\left(C_{r}\right)$, calcium test and Motokawa's flicker test.

Let $(B)$ stand for the systolic pressure and $(P)$ for the puls: frequency at recumbent position, and (b) for the systolic pressure and (p) for the pulse frequency at standing position, and $C_{B}$ and $C_{0}$ may be determined by the following formulae :

$$
C_{B}=\frac{|B-b|}{B} \quad C:=\frac{|P-p|}{P}
$$

The mean values of $C_{B}$ and $C$ in normal human subjects were 0.078 and 0.104 , respectively. In calcium tests, $0.01 \mathrm{mg} / \mathrm{kg}$ of adrenaline was subcutaneously injected and $30 \mathrm{~min}$. afterwards, the decrement of serum Ca was estimated, taking $2.7 \mathrm{mg} / \mathrm{dl}$ as the upper limit of the normal value. In the flicker test, the retina was stimulated. with electric current of 20 cycles at the room temperature of 18 $23^{\circ} \mathrm{C}$. The current was gradually increased till flickers began to appear in sight (at $S_{1} \mu \mathrm{A}$ ) and then it was gradually weakened till the flickers disappeared (at $S_{2}$ $\mu \mathrm{A})$. The flicker value $(\Delta S)$ was computed by the following formula :

$$
\Delta S=S_{1}-S_{2}
$$

TABLE VI. Autonomic Nervous Function of Patients with Climacteric Disorder.

\begin{tabular}{c|c|c}
\hline Autonomic nervous function & Normal & Abnormal \\
\hline$C_{B}(15$ cases $)$ & $6.7 \%$ & $93.3 \%$ \\
$C_{\dot{B}}(15)$ & $26.7 \%$ & $73.3 \%$ \\
Ca test $(17)$ & $0 \%$ & $100 \%$ \\
$\Delta S$ & $21.2 \%$ & $78.8 \%$
\end{tabular}

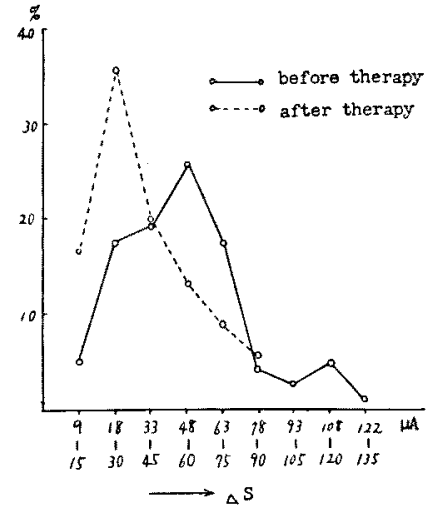

Fig. 20. Changes of $\Delta S$ values of climacteric patients.

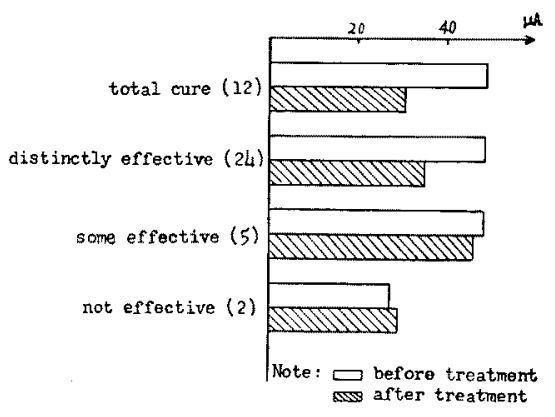

Fig. 21. Efficacy of estrogen and $\triangle \mathrm{S}$ value. 
The normal range of $\Delta S$ was taken to be less than $30 \mu \mathrm{A}$. The autonomic nervous function, as shown in Table VI, was found to be abnormal in most of the climacteric disturbance cases, though the results of different tests showed no much correlation to each other. The distribution of $\Delta S$ values after initiation of therapy for climacteric disturbances, as shown in Fig. 20, shifted to the normal side, that is, $\Delta S$ is decreased. Besides this, as shown in Fig. 21, the decrement of $\Delta S$ after therapy is increased with the effectiveness of the treatment.

Why is hormone administration effective against climacteric disturbances ?

It has been thus ascertained that climacteric disturbance is less closely correlated with hormone secretion but more with autonomic nervous function, but why is it that hormone administration is effective in treatin r such disturbances? As a clue to this question, we tried to evaluate the influence of some hormones on the function of diencephalon, namely, $\mathrm{QO}_{2}$ and the secretion of $\mathrm{Ach}, \mathrm{ChE}$, allaline phosphatase and Gomoriphil substance. As shown in Fig. 22, the diencephalic $\mathrm{QO}_{2}, 6$ hours after injection of $1 \gamma$ of estradiol, was lowered, rose after $10 \gamma, 100 \gamma$ and $1,000 \gamma$ of it, but the rise after $1,000 \gamma$ was not so large as that after $100 \gamma$. Progesterone also caused the maximum rise after $100 \gamma$. After pregnanediol, known as ineffective as hormone but effective in treating climacteric disturbances, the diencephalic $\mathrm{QO}_{2}$ increased, but testosterone caused only slight change in the value. When castrated rats were injected with 500 I.U. of serotropin (PMS), the $\mathrm{QO}_{2}$ value dropped significantly.
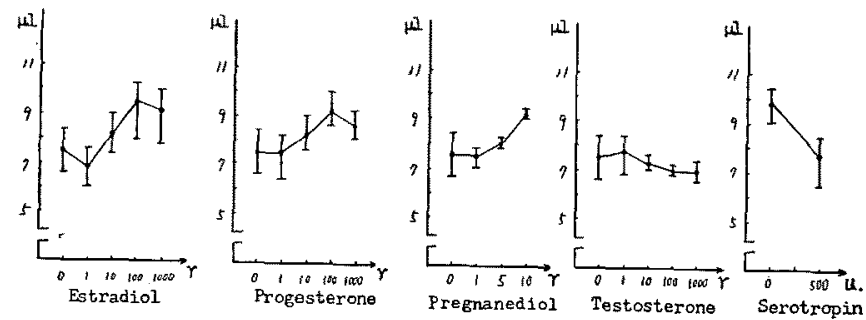

Fig. 22. Diencephalic $Q_{2} 6 \mathrm{hrs}$. after hormone injection.

As shown in Table VII, 6 and 9 hours after injection of $0.04 \gamma$ of estradiol benzoate, the alkaline phosphatase (Al-Ph) content in the diencephalon of rat was moderately lowered, but very perceptibly 9 hours after $0.4 \gamma$ of estradiol. After $200 \gamma$ of the latter, the value began to decrease in 6 hours and fell to the lowest level in 12 hours and remained there till the 48 hours, then tended to normalize. Nearly no effect was discernible after $1,000 \gamma$ of progesterone, and only a moderate decrease of the $\mathrm{Al}-\mathrm{Ph}$ content was observed 6 hours after $500 \gamma$ of testosterone propionate. 
TABLE VII. Effect of Hormones on Alkaline Phosphatase Content in Nucleus Supraopticus

\begin{tabular}{|c|c|c|c|c|c|c|c|c|c|c|c|}
\hline \multicolumn{2}{|c|}{$\begin{array}{c}\text { After injection of } \\
\text { hormone }\end{array}$} & Control & 1 & 6 & 9 & 12 & 24 & 36 & 48 & 72 & $96 \mathrm{hrs}$ \\
\hline \multirow{3}{*}{ Estradiol } & $0.04 \gamma$ & 0 & 0 & -3 & -3 & 0 & 0 & 0 & 0 & 0 & 0 \\
\hline & $0.4 \gamma$ & 0 & 0 & -3 & -5 & -3 & -2 & & & & \\
\hline & $200 \gamma$ & 0 & 0 & -3 & -4 & -5 & -5 & -5 & -5 & -4 & -3 \\
\hline \multicolumn{2}{|c|}{ Progesterone $1000 \gamma$} & 0 & 0 & 0 & -1 & 0 & 0 & & & & \\
\hline \multicolumn{2}{|c|}{ Testosterone } & 0 & -1 & -4 & -3 & 0 & 0 & & & & \\
\hline
\end{tabular}

Note : (-) decrease

As shown in Table VIII, the Gomoriphil substance in the supraoptic nuclei is affected more by the large doses of estradiol than by the small doses of it, but more by the small doses $(10 \gamma)$ than by the large doses $(100 \gamma)$ of testosterone. After $10 \gamma$ of progesterone, the Gomoriphil substance began to increase in 3 hours, attaining the maximum content in 6 hours, but the content rose abruptly in 12 hours after $1,000 \gamma$.

TABLE VIII. Effect of Hormone on the Gomoriphil Substance in the Nucleus Supraopticus

\begin{tabular}{cr|cccc}
\hline \multicolumn{2}{l|}{$\begin{array}{l}\text { After injection } \\
\text { of hormone }\end{array}$} & Control & 3 & 6 & $12 \mathrm{hrs}$ \\
\hline Estradiol & $1 \gamma$ & + & + & + & + \\
$"$ Testosterone & $100 \gamma$ & + & + & W & Ht \\
" $10 \gamma$ & + & + & + & + \\
Progesterone $1000 \gamma$ & $+10 \gamma$ & + & + & + & + \\
" & $1000 \gamma$ & + & + & + & +
\end{tabular}

Note : $(+)$ increase

As shown in Fig. 23, the diencephalic Ach content was greatly increased after $100 \gamma$ of estradiol benzoate, but slightly decreased after $1 \gamma-100 \gamma$ of progesterone and a little after $5 \gamma$ of pregnanediol. After $1 \gamma$ of testosterone propionate, the Ach content fell a little, but sharply increased after $100 \gamma$ and $1,000 \gamma$. In the
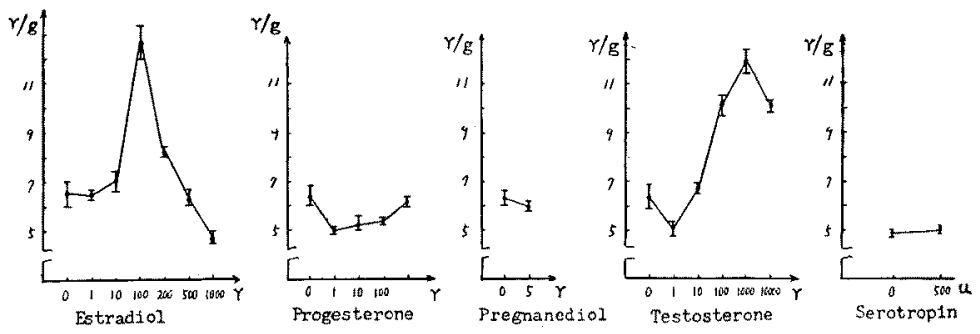

Fig. 23. Diencephalic Ach after hormone injetion. 
castrated rat injected with 500I.U. of serotropin (PMS), the Ach content remained unchanged.

As shown in Table IX, the ChE content in the supraoptic nuclei of the rat was not much affected after $1 \gamma$ of estradiol, but increased a little in 3 hours and decreased moderately in 12 hours after giving $10 \gamma$ of estradiol. After $100 \gamma-200 \gamma$, ChE content moderately increased in 3 hours and markedly decreased in 12 hours, the effect being more significant after $200 \gamma$ than after $100 \gamma$ of the dose. When the dose was raised above $500 \gamma$, the increase at the 3 hours was not observed, while the decrease became apparent after 48 hours. No significant changes were observed after the injection of progesterone or pregnanediol. ChE increased after $1 \gamma$ of testosterone propionate and after the doses of $10 \gamma$ the increase occurred in earlier stage of observation, although the degree of the increment was rather mild. Injection of $500 \mathrm{I} . \mathrm{U}$. of serotropin (PMS) caused no change in the ChE content in castrated rats.

TABLE IX. Effect of Hormone on Cholinesterase Activity of Nucleus Supraopticus

\begin{tabular}{l}
\hline After injection of hormone \\
\hline Estradiol
\end{tabular}

Thus, it was found that the factors governing the diencephalic function $-\mathrm{QO}_{2}$, $\mathrm{Al}-\mathrm{Ph}$, the Gomoriphil substance, $\mathrm{Ach}, \mathrm{ChE}$ - are all under the influence of the hormones tested, either positively or negatively, and in particular, the contents of Ach and $\mathrm{ChE}$, which are considered to have close relationship with the function of autonomic nerves, are strongly influenced by the hormones. Besides this, the more effective hormones against climacteric disturbances showed the more stronger effect on the diencephalic function. 
Is rejuvenation of the sex center possible?

Although the sex center is now generally considered to be located in hypothalamus, it is not decided which nuclei represent the center as yet. In this study, therefore, the part of hypothalamus containing the supraoptic, paraventricular and tuberal nuclei was taken as to represent the sex center.

As stated above, when the hypothalamus becomes aged, the secondary fluorescence after acridin-orange staining will have longer wave-length. Hence, we adopted the method of comparing the secondary fluorescence from so-called sex center of old rats of same maturity, devided into experimental and control groups, for the evaluation of rejuvenative effects of various agents. By such. a method, it was demonstrated that royal jelly and orotic acid had the rejuvenative effect.

\section{DISCUSSION}

There is no disagreement to the fact that climacterium is the commencement of senescence, however differences of the opinion exsist in regarding the generally accepted hypothesis of the senescence initiating in the ovary. Our investigators led to the conclusion that senescence begins rather in the hypothalamus, and that this process can be alleviated by the administration of royal jelly or orotic acid. Sex center is located in the hypothalamus, hence it could be deduced that these two agents also exerts their rejuvenating effect on the sex center. When royal jelly is injected to women in menopausal stage, menses-like hemorrhage is sometimes observed.

Hitherto, it has been generally accepted that climacteric disturbances are caused by deficiency of estrogen due to retrogression of the ovarian function. But the excretion of estrogen in urine was found not always decreased in patients with climacteric disturbances. In these cases, the follicle-stimulating hormone (FSH) was found to be increased in many cases but in some cases this increase was not found. Besides this, there are cases in which moderate increase of the hormone was found but without any symptom of climacteric disturbance. Thus, the change of FSH content did not show parallelism with the manifestation of such symptoms, neither their contents of 17-0H-corticoid, 17-KS, ACTH and TSH showed any correlation with the grade of climacteric disturbances. Yet, almost all the patients showed instability of the autonomic nervous function. From these findings, we may infer that climacteric disturbances are caused by a primary instability of the autonomic nervous function brought about by the aging of the nervous center and a secondary dysfunction of the autonomic nervous center due to the senescence of the hormonal organs. It is hardly possible to maintain the endocrine balance permanently on the level of full maturity, but even without bothering about the hormonal balance, we may correct the dysfunc- 
tion of the autonomic nervous center. For treating climacteric disturbances, repair of the impaired function of the autonomic nervous center should be the objective. The effectiveness for repairing the autonomic nervous function is the strongest in estrogen, next in testosterone, weak in progesterone and barely detectable in pregnanediol. Gonadotrophin also proved effective, but only slightly. The efficacy of these hormones in repairing the impaired autonomic nervous function runs nearly parallel with their efficacy against climacteric disturbances. Slow intravenous injection of $0.5 \%$ solution of procain chloride, known as devoid of hormonal effect but effective in regulating the autonomic nervous function, also proved as effective as estrogen injection in alleviating such disturbances.

The current policy of treating climacteric disturbances by attempting replenishment of deficient hormones is misdirected. When some hormonal treatmont is contemplated then, the aim of the treatment must be the autonomic nervous center. Consequently, hormone treatment against climacteric disturbances need not be continued long, a course of hormone administration of less than a week being often sufficient for the purpose. If such a short course proved to be ineffective, some other therapeutic procedures should be resorted to. When 3-4 different methods in succession prove to be utterly unsuccessful, then the case undoubtedly represents a case of disturbances caused by emotional conflict, and is uncurable unless she is duly treated as a psychosomatic patient. The subject of psychosomatic disorder will be treated in another report.

\section{CONCLUSION}

The present authors' investigation on climacterium, climacteric disturbances and the possibility of rejuvenating the sex centers led to the following conclusions :

1. The hypothalamus falls into senescence earlier than the ovary. Therefore, the currently accepted opinion that climacteric changes begin in the ovary and then proceed to the hypothalamo-hypophyseal system is unfounded.

2. Some of the climacteric disturbances are psychosomatic and some are endocrino-vegetative. The results of our study led us to conclude that the latter are not necessarily correlated with deficiency of estrogen or increases of gonadotrophin, but from a dysfunctional syndrome of the autonomic nervous center due to the effect of senescence of the diencephalon and the hormonal organs.

3. Estrogen proved to be most effective in correcting such a dysfunction of the autonomic nervous center, but androgen, gonadotrophin, pregnanediol, and even the nonhormonal procaine are also effective.

4. The objective of treating climacteric disturbances is to correct the dysfunctioned autonomic nervous center. It is impossible to expect success after long persistent treatment with hormones only. When a course proves unavailing within a week, another therapy must be contemplated, and if 3-4 methods fail 
to effect, psychosomatic disorder should be suspected. The doses of the hormones used need not be large, $1 \mathrm{mg}$ of estrogen, $10 \mathrm{mg}$ of androgen or $10 \mathrm{mg}$ of procaine per day will be quite sufficient for the purpose.

5. It was demonstrated that treatment of climacteric disturbances should succeed by merely bringing the autonomic nervous function back to order, without attending to the function of the sex center, and also that the attempt at rejuvenating the hypothalamus, the seat of the center, is a hopeful enterprise.

\section{References}

1) Squires, A.H., M. Clin. of North. Amer., 1952, 36, 515.

2) Kurzrok, R., Endocrinol., 1932, 16, 366.

3) Tamis, A.B., A.J.O.G., 1934, 28, 48.

4) Berger, J. \& Keller, M., Gynaecologia, 1954, 137, 250.

5) Zondek, B., Klin. Wschr., 1930, 9, 393.

6) Engel, E.T., Arch. Gynäk., 1938, 166, 131.

7) Henderson, W.R. \& Rowland, I.W., Brit. M. J., 1938, 1, 1094.

8) Witschi, E. \& Riley, G.M., Endocrinol., 1940, 26, 565.

9) Fluhmann, C.F., A.J.o.G., 1930, 20, 1.

10) Albright, F., Endocrinol., 1936, 20, 24.

11) Engelhart, E. \& Tscherne, E., Zbl. Gynäk., 1936, 60, 790. 